\title{
A grey zone of hyperamylasemia following endoscopic retrograde cholangiopancreatography: follow-up and differential diagnosis from acute pancreatitis
}

\author{
Mikail Cakir, Adnan Hut, Okan Murat Akturk, Busra Ekinci Biçkici, Dogan Yildirim \\ Department of General Surgery, Haseki Training and Research Hospital, University of Health Sciences, Istanbul, Turkey
}

Videosurgery Miniinv

DOI: https://doi.org/10.5114/wiitm.2020.94545

\begin{abstract}
Introduction: Endoscopic retrograde cholangiopancreatography $(E R C P)$ is a tool often used for treating and diagnosing pancreaticobiliary diseases. One of the important complications of ERCP is pancreatitis. Even though transient hyperamylasemia is a more common and benign situation, it must be distinguished from post-ERCP pancreatitis.

Aim: To define the risk factors associated with post-ERCP pancreatitis (PEP) and tried to identify a cutoff about laboratory findings for positive or negative prediction.

Material and methods: We reviewed the medical files of patients who underwent ERCP for choledocholithiasis in a retrospective cohort study. The primary outcome is the risk factors associated with PEP. Receiver operator characteristics analysis was carried out for determination of cut-offs for laboratory parameters.

Results: The presence of cholangitis $(p=0.018)$, Wirsung cannulation $(p=0.008)$, presence of abdominal pain at $12^{\text {th }}$ and $24^{\text {th }} h(p<0.001)$, amylase level at $12^{\text {th }} h(p<0.001), C$-reactive protein $(C R P)$ levels at $6^{\text {th }}$ and $12^{\text {th }} h(p=$ 0.001 and $p<0.001)$, white blood cells (WBC) levels at $6^{\text {th }}$ and $12^{\text {th }} h(p=0.001$ and $p<0.001)$ were significant for development of PEP. CRP levels above $8 \mathrm{mg} / \mathrm{l}$ and WBC above $10 \times 10^{3}$ had negative predictive values over $70 \%$ and $90 \%$ respectively.

Conclusions: Physical examination and inflammatory parameters are important in diagnosis of PEP. CRP and WBC have high negative predictivity and sensitivity. Amylase level increase was most apparent $12 \mathrm{~h}$ after ERCP and significantly higher $(p<0.001)$ for the development of PEP. The first abdominal pain evaluation is meaningful at the $12^{\text {th }} h$ timepoint because insufflation during the procedure and other causes of abdominal pain may result in misinterpretation.
\end{abstract}

Key words: acute pancreatitis, endoscopic retrograde cholangiopancreatography, hyperamylasemia.

\section{Introduction}

Endoscopic retrograde cholangiopancreatography (ERCP) is one of the most commonly used diagnostic and therapeutic interventional modalities for pancreaticobiliary diseases (Photo 1). However, recent trends over the last two decades have reduced its employment as a diagnostic procedure, while non-invasive imaging techniques have be- come more popular as a diagnostic tool [1]. The most common use and indication for ERCP is the removal of stones from the biliary tree; other indications are malignant, inflammatory or postoperative strictures, ampullary masses causing obstruction, sphincter of Oddi dysfunction, bile leaks due to gallbladder and liver surgery, cholecystitis, cholangitis, acute, recurrent or chronic pancreatitis, pancreas divisum, pancreatic duct leaks, fluid collections, drainage of cystic

\section{Address for correspondence}

Okan Murat Akturk MD, Department of ???, Istanbul Haseki Training and Research Hospital, University of Health Sciences, Istanbul,

Turkey, phone: +90 9532320 6983, e-mail: omakturk@gmail.com 


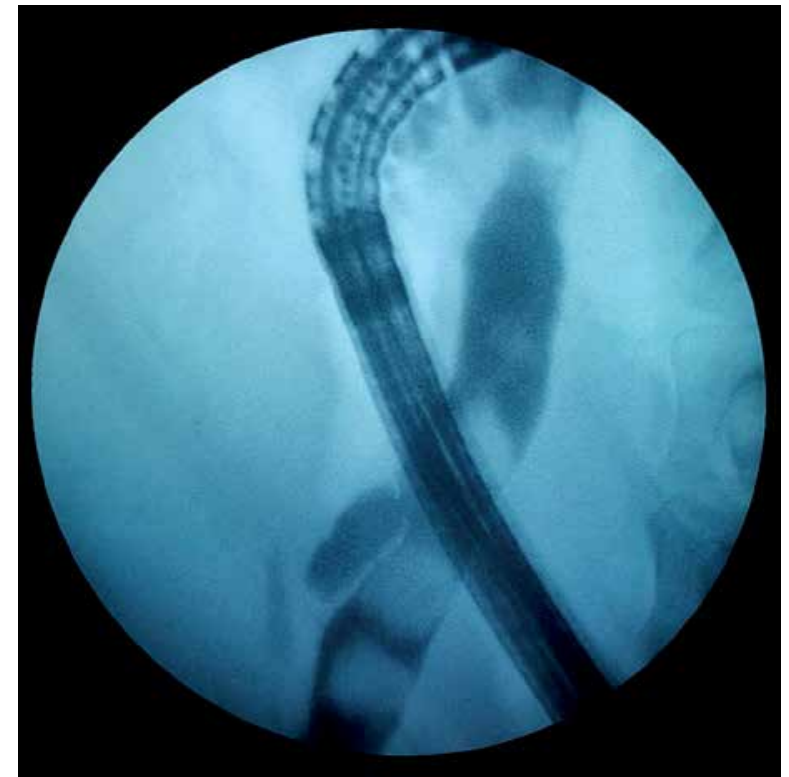

Photo 1. Choledocholithiasis. From the archives of Endoscopic Surgery Unit

lesions of pancreas, and stenting of pancreatic tumors. The procedures are sphincterotomy, dilatation and removal of stones, drainage and stenting, cholangiography biopsy and manometry [1, 2].

Although ERCP is considered to be a safe procedure, it may have significant complications such as cholangitis (1-1.4\%), hemorrhage (2\%), pancreatitis $(1-15.7 \%)$, perforation $(<1 \%)$, and strictures developing over months to years [3]. The incidence of post-ERCP pancreatitis (PEP) widely varies according

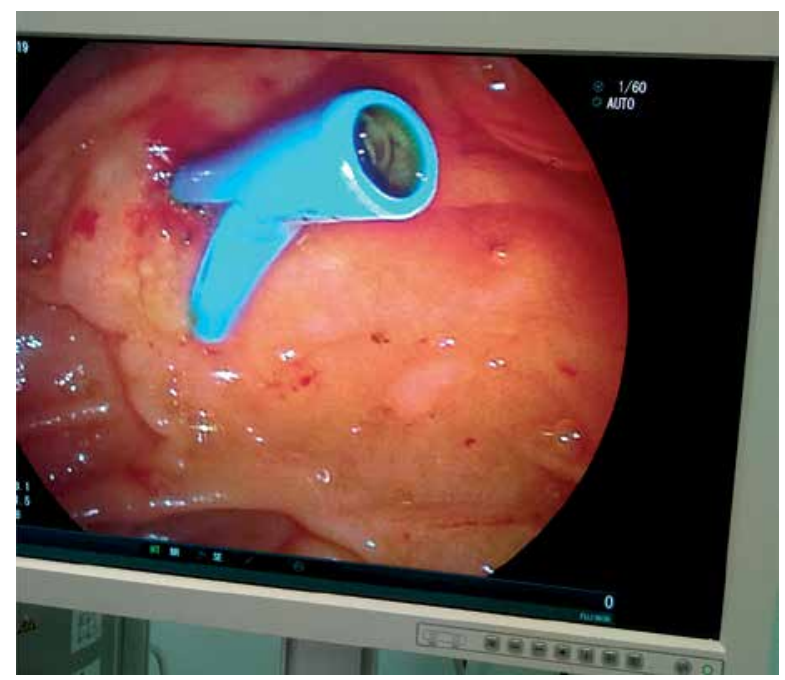

Photo 2. Stent in the duodenal papilla. From the archives of Endoscopic Surgery Unit to studies and definitions, as much as between $1 \%$ and $15.7 \%[3,4]$. Serum pancreatic enzymes are elevated because of minor trauma to the pancreatic parenchyma imputable to manipulations during ERCP; however, asymptomatic hyperamylasemia is a more frequent situation that should be distinguished from real acute PEP and is reported between $6.8 \%$ and $70 \%[5]$.

ERCP is performed on an outpatient basis in most hospitals (Photo 2). The first control of amylase and hemogram is noted at 2 or $4 \mathrm{~h}$ after ERCP. LaFerla et al. [6] were early to identify that serum amylase levels rose quickly $2 \mathrm{~h}$ after ERCP. PEP is defined as pancreatic type abdominal pain with increased levels of serum amylase more than 3 times the upper normal limit at $24 \mathrm{~h}$ after ERCP [7]. To standardize the diagnosis, revised Atlanta Criteria have been introduced which take imaging and organ failure into consideration [8]. Furthermore, performing a physical examination at 2 or $4 \mathrm{~h}$ after ERCP is controversial due to the effect of anesthesia and the distention of the abdomen due to air insufflation, as well as other causes such as perforation [9]. Pancreatitis may result in pancreatic infection-sepsis, necrosis, multi-organ failure and eventually death. Once a patient is diagnosed with PEP, every effort should be made to prevent complications of pancreatitis.

\section{Aim}

The aim of this study is to identify the laboratory markers and patient characteristics that may be used to predict or to define the difference between transient hyperamylasemia $(\mathrm{TH})$ and real acute pancreatitis.

\section{Material and methods}

\section{Study design and patient selection}

Medical files of patients with choledocholithiasis who underwent ERCP were evaluated in a retrospective cohort study at the General Surgery Department between November 2015 and October 2018. Local ethics committee approval was granted by the number of 528/21.06.2018, with full confirmation of the Helsinki Declaration. Inclusion criteria were as follows: all emergency and elective choledocholithiasis cases were included if the patients had their first ERCP. Only successfully completed ERCPs were taken into account. Emergency cases were the pa- 
tients with choledocholithiasis related cholangitis or mechanical icterus leading to deterioration of liver functions. Elective cases were the patients with choledocholithiasis with no biochemical abnormality; for these patients ERCP was scheduled within 23 weeks. Biliary pancreatitis cases were excluded.

\section{Data collection}

The patients were followed up for at least $24 \mathrm{~h}$ by checking amylase, white blood cell (WBC) count, alanine aminotransferase (ALT), aspartate aminotransferase (AST), alkaline phosphatase (ALP), gammaglutamyl transferase (GGT), and bilirubin levels at 6 and $12 \mathrm{~h}$ after ERCP with physical examinations. If laboratory abnormalities with pancreatic type abdominal pain were detected at these observational timepoints, the patients were checked again at $24 \mathrm{~h}$; otherwise, they were discharged. The patients with other complications such as perforation, bleeding with or without $\mathrm{TH}$, and PEP were excluded to maintain homogeneity and easy assessment of hyperamylasemia in the study group. Hence, 75 patients with PEP and 168 patients with TH constituted our study population.

\section{The interventional procedure}

The ERCP procedures were performed by two surgical interventional gastrointestinal endoscopists with experience of more than 1000 thousand upper and lower tract gastrointestinal endoscopies and more than 100-120 ERCPs annually in the last 5 years. Patients were hospitalized after at least $8 \mathrm{~h}$ fasting and the ERCP procedure was carried out in the operating room under sedation analgesia anesthesia. A sphincterotome was inserted into the papilla; if the endoscopist managed to advance the sphincterotome, controlled small amounts of contrast medium was given under fluoroscopy to reveal opacification of the common bile duct (CBD) or pancreatic duct (PD). In circumstances of pancreatic duct opacification, the sphincterotome was withdrawn and manipulated in the direction of the CBD. If cannulation of the CBD was evidenced with opacification, a $10 \mathrm{~mm}$ sphincterotomy was performed. If the technique failed, a guidewire was used to ease the cannulation, and a guidewire was also used at the failed first attempt of cannulation of the papilla with the sphincterotome. In the case of failed papilla cannulation, a precut sphincterotomy was performed by a needle knife papillotome. Following papillotomy, the sphincterotome with guidewire was again inserted into the CBD and sphincterotomy was completed. Balloon and basket catheters were inserted into the CBD for extraction of stones. This standardized procedure was performed in all patients. None of the patients were given perioperative medication for pancreatitis prevention and PD stents were not left placed.

\section{Definitions}

PEP and TH are different entities. PEP needs a lengthened hospitalization whereas a $\mathrm{TH}$ patient can be discharged.

The current PEP definition was made according to Cotton criteria and revised Atlanta classification [7, 8]. The general definition is persisting and worsening abdominal pain at least $24 \mathrm{~h}$ with an amylase level of more than 3 times the upper limit at the $24^{\text {th }} \mathrm{h}$.

Difficult cannulation was accepted as the achievement of cannulation after $15 \mathrm{~min}$ from the entrance of duodenoscope due to a greater number of attempts, and need for precut sphincterotomy.

\section{Statistical analysis}

IBM SPSS for Windows version 21.0 (Armonk, NY: IBM Corp) was used for statistical analysis. Descriptive statistics were given as number and percentage for categorical variables, and mean and standard deviation for numerical variables. If the numerical variables were normally distributed, Student's $t$-test was used to compare two independent groups. If the numerical variables were not normally distributed, the Mann-Whitney $L$ test was used to compare two independent groups. The $\chi^{2}$ test was used for the rates of categorical variables among groups. Determinant factors were analyzed logistic regression analysis. The cut-off value was analyzed by ROC curve analysis. $P$-values less than 0.05 were considered statistically significant.

\section{Results}

The mean age of patients having post-ERCP hyperamylasemia was $58.8 \pm 13.3$ (range: 24-80). Forty-eight (64\%) patients were female and 27 (36\%) were male. Forty-two (56\%) patients had elective-planned ERCP and 33 (44\%) patients had emergent ERCP, of whom 6 (8\%) also had cholangitis. Sixty-nine (92\%) patients had no cholangitis. 
Difficult ERCP was seen in $8(10.7 \%)$ patients and Wirsung cannulation occurred in 12 (16\%) patients. Forty-eight (64\%) patients had no abdominal pain, while 15 (20\%) patients had abdominal pain at the $12^{\text {th }} \mathrm{h}$ but no pain at the $24^{\text {th }} \mathrm{h}$. Twelve $(16 \%)$ patients had abdominal pain at the $12^{\text {th }}$ and $24^{\text {th }} \mathrm{h}$; these patients were evaluated as having PEP. The mean amylase levels were $468(\mathrm{U} / \mathrm{l})(190-852)$ at the $6^{\text {th }} \mathrm{h}$, $364.3(\mathrm{U} / \mathrm{l})(94-748)$ at the $12^{\text {th }} \mathrm{h}$ and $799.3(\mathrm{U} / \mathrm{l})$ (517-1283) at the $24^{\text {th }} \mathrm{h}$. The mean CRP levels were $16.9 \mathrm{mg} / \mathrm{dl}(4-138)$ at the $6^{\text {th }} \mathrm{h}, 21.5 \mathrm{mg} / \mathrm{dl}(5-140)$ at the $12^{\text {th }} \mathrm{h}$ and $98.3(35-185) \mathrm{mg} / \mathrm{dl}$ at the $24^{\text {th }} \mathrm{h}$. The mean WBC counts were $11.0 \times 10^{3}(1.5-21.2)$ at the $6^{\text {th }} \mathrm{h}, 10.2 \times 10^{3}(6-19.3)$ at the $12^{\text {th }} \mathrm{h}$ and $16.1 \times$ $10^{3}(10-21)$ at the $24^{\text {th }} \mathrm{h}$ (Table I).

For the development of PEP and differentiation from $\mathrm{TH}$ variables were compared and evaluated in Table II. The presence of cholangitis $(p=0.018)$, Wir-

Table I. Demographics and characteristics of the study group

\begin{tabular}{|c|c|c|}
\hline Parameter & Mean \pm SD & $\begin{array}{l}\text { Min.-max. } \\
\text { (medium) } \\
\text { or } n(\%)\end{array}$ \\
\hline Age & $58.8 \pm 13.3$ & $24-80(60)$ \\
\hline Sex, $n(\%)$ & $\begin{array}{l}\text { Female } \\
\text { Male }\end{array}$ & $\begin{array}{l}48(64) \\
27(36)\end{array}$ \\
\hline Elective/emergent & $\begin{array}{l}\text { Elective } \\
\text { Emergent }\end{array}$ & $\begin{array}{l}42(56) \\
33(44)\end{array}$ \\
\hline Cholangitis & $\begin{array}{l}\text { Absent } \\
\text { Present }\end{array}$ & $\begin{array}{c}69(92) \\
6(8)\end{array}$ \\
\hline Difficult ERCP & $\begin{array}{c}\text { Not } \\
\text { Difficult }\end{array}$ & $\begin{array}{c}67(83.9) \\
8(10.7)\end{array}$ \\
\hline Wirsung cannulation & $\begin{array}{l}\text { Absent } \\
\text { Present }\end{array}$ & $\begin{array}{l}63(84) \\
12(16)\end{array}$ \\
\hline Abdominal pain & $\begin{array}{c}\text { No pain } \\
\text { Pain at } 12^{\text {th }} \mathrm{h} / \mathrm{ho} \text { pain } \\
\text { at } 24^{\text {th }} \mathrm{h} \\
\text { Pain at } 12^{\text {th }} \text { and } 24^{\text {th }} \mathrm{h}\end{array}$ & $\begin{array}{l}48(64) \\
15(20) \\
12(16)\end{array}$ \\
\hline Amylase [U/I] & $\begin{array}{l}6^{\text {th }} \\
12^{\text {th }} \\
24^{\text {th }}\end{array}$ & $\begin{array}{l}468.0 \pm 153.5 \\
364.3 \pm 161.6 \\
799.3 \pm 234.6\end{array}$ \\
\hline CRP $[\mathrm{mg} / \mathrm{dl}]$ & $\begin{array}{l}6^{\text {th }} \\
12^{\text {th }} \\
24^{\text {th }} \\
\end{array}$ & $\begin{array}{l}16.9 \pm 22.4 \\
21.5 \pm 27.0 \\
98.3 \pm 57.6\end{array}$ \\
\hline WBC $\left[\times 10^{3}\right]$ & $\begin{array}{l}6^{\text {th }} \\
12^{\text {th }} \\
24^{\text {th }}\end{array}$ & $\begin{array}{l}11.0 \pm 2.9 \\
10.9 \pm 2.5 \\
16.1 \pm 3.3\end{array}$ \\
\hline PEP & & $12(18)$ \\
\hline $\mathrm{TH}$ & & $63(84)$ \\
\hline
\end{tabular}

sung cannulation ( $p=0.008)$, presence of abdominal pain at the $12^{\text {th }}$ and $24^{\text {th }} \mathrm{h}(p<0.001)$, amylase level at the $12^{\text {th }} \mathrm{h}(p<0.001)$, CRP levels at the $6^{\text {th }}$ and $12^{\text {th }} \mathrm{h}(p=0.001$ and $p<0.001)$, and WBC levels at the $6^{\text {th }}$ and $12^{\text {th }} \mathrm{h}(p=0.001$ and $p<0.001)$ were significantly higher for development of PEP. Amylase level decreased in patients who did not have PEP. CRP levels increased in both groups.

The most important factors for the development of PEP were Wirsung cannulation and the WBC count at the $6^{\text {th }} \mathrm{h}$ (Table II).

Receiver operating characteristic (ROC) curves were plotted for CRP to identify patients with PEP, with a statistically significant area under the curve of 0.690 (95\% confidence interval (CI): 0.501-0.879) (Figure 1). We also calculated the positive predictive value (PPV), negative predictive value (NPV), positive likelihood (+LH) and negative likelihood (-LH) for CRP at a cut-off value of $8 \mathrm{mg} / \mathrm{dl}$, which had a negative predictive value in approximately $70 \%$ of patients with a similar sensitivity (Table III).

ROC curves were also plotted for WBC to identify patients with PEP, with a statistically significant area under the curve of $0.732(95 \% \mathrm{Cl}$ : $0.552-$ 0.912) (Table IV). We also calculated the PPV, NPV, $+\mathrm{LH}$ and $-\mathrm{LH}$ for RDW at a cut-off value of $10 \times 10^{3}$,

Table II. List of significant parameters related to post-ERCP pancreatitis

\begin{tabular}{|ll|}
\hline Parameter & $P$-value \\
\hline Sex & 0.655 \\
\hline Emergent or elective & 0.648 \\
\hline Cholangitis present & 0.018 \\
\hline Difficult ERCP & 0.079 \\
\hline Wirsung cannulation & $0.008^{*}$ \\
\hline Amylase at $6^{\text {th }} \mathrm{h}$ & 0.190 \\
\hline Amylase at $12^{\text {th }} \mathrm{h}$ & $0.000^{*}$ \\
\hline Abdominal pain at $12^{\text {th }} \mathrm{h}$ & $0.000^{*}$ \\
\hline Abdominal pain at $24^{\text {th }} \mathrm{h}$ & $0.000^{*}$ \\
\hline CRP levels at $6^{\text {th }} \mathrm{h}$ & $0.001^{*}$ \\
\hline CRP levels at $12^{\text {th }} \mathrm{h}$ & $0.000^{*}$ \\
\hline WBC levels at $6^{\text {th }} \mathrm{h}$ & $0.001^{*}$ \\
\hline WBC levels at $12^{\text {th }} \mathrm{h}$ & $0.000^{*}$ \\
\hline
\end{tabular}

$W B C$ - white blood cell count, CRP - C-reactive protein. Significant results are indicated with an *(Bonferroni correction). 
which had a negative predictive value in approximately $90 \%$ of patients with a sensitivity over $80 \%$ (Table IV).

\section{Discussion}

Several factors have been identified as a risk for development of PEP. Female sex has been found to be related to the development of PEP $[10,11]$. This finding was not confirmed by our study model ( $p=$ 0.655). However, this finding is in agreement with the study by Katsinelos et al. [4].

Age has also been shown to be a significant factor in the development of PEP. Age younger than 60 years is found to be related to disease in several prospective studies; this finding was confirmed in our study. Overall, our patient population with hyperamylasemia was younger than 60 years of age $[12,13]$. There was no significant difference in age between the PEP and transient hyperamylasemia groups $(p=0.281)$.

Urgent endoscopic biliary drainage was reported to be important in the treatment of acute cholangitis in a study by Boender et al. [14], in 1995, pointing out that adverse events due to persistent cholangitis became more frequent as the delay between onset and biliary drainage increased. This was later supported by Tan et al., in their large group study, which reported marginally significant improvement of 30day mortality in patients who underwent ERCP within $24 \mathrm{~h}$ after hospitalization [15]. Accordingly, we adopted the policy of urgent ERCP as early as possible after the patient was stabilized [16]. In our regression analysis, we found a significant increase in postprocedural PEP in patients who underwent urgent ERCP for cholangitis, even though it was a small subset of patients $(p=0.018)$.

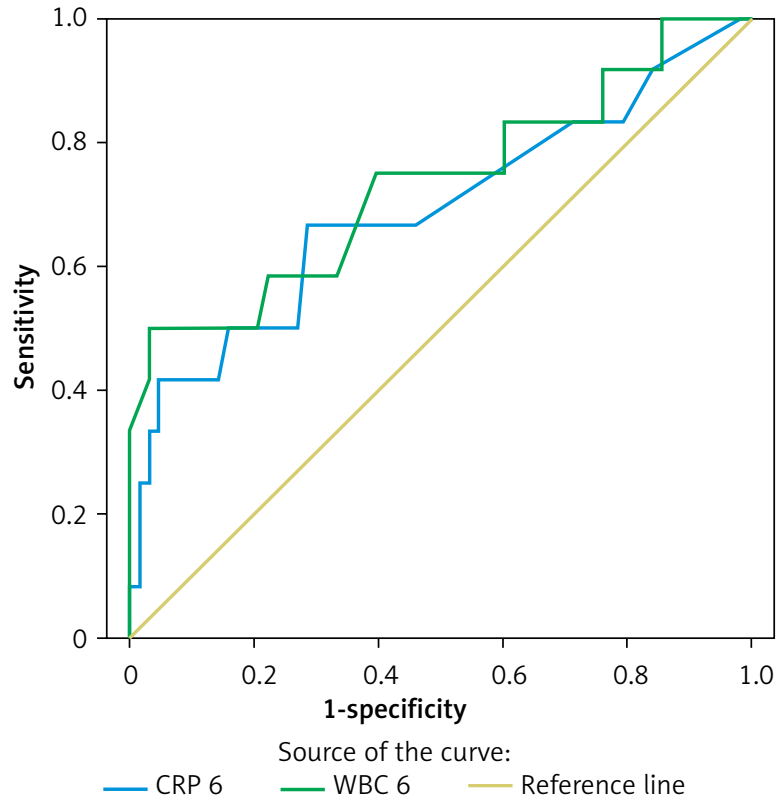

Figure 1. Receiver operating characteristic curves of CRP and WBC for post-ERCP pancreatitis

It is hard to define what makes an ERCP difficult and cannulation prolonged, but prolonged manipulation may damage the pancreatic duct and thus increase PEP. A similar strategy was carried out by our endoscopist surgeons and our findings confirm that as in previous studies, a difficult ERCP was significantly correlated with the incidence of PEP $(p=0.008)$ [17].

ERCP is commonly performed on an outpatient basis. The patients are discharged 2-4 $\mathrm{h}$ after follow-up if no laboratory or clinical abnormalities are detected. The patients are advised to refer to the emergency department if there is any discomfort such as abdominal pain, vomiting, or fatigue. Since pancreatitis, perforation, bleeding, and cholangitis

Table III. Sensitivity, specificity, +LR and -LR, positive predictive value, negative predictive value of C-reactive protein levels for post-ERCP pancreatitis at optimal cut-off level

\begin{tabular}{|lcccccc|}
\hline CRP & $\begin{array}{c}\text { Sensitivity } \\
(95 \% \mathrm{Cl})\end{array}$ & $\begin{array}{c}\text { Specificity } \\
(95 \% \mathrm{Cl})\end{array}$ & $+\mathrm{LR}$ & $-\mathrm{LR}$ & $\begin{array}{c}\text { Positive predictive value } \\
(95 \% \mathrm{Cl})\end{array}$ & $\begin{array}{c}\text { Negative predictive } \\
\text { value }(95 \% \mathrm{Cl})\end{array}$ \\
\hline$>8 \mathrm{mg} / \mathrm{dl}$ & $75.00(42.81-94.51)$ & $40.32(28.05-53.55)$ & 1.26 & 0.62 & $19.57(14.20-26.34)$ & $70.79(62.99-77.53)$ \\
\hline
\end{tabular}

Table IV. Sensitivity, specificity, $+L R$ and $-L R$, positive predictive value, negative predictive value of white blood cell count for post-ERCP pancreatitis at optimal cut-off level

\begin{tabular}{|lcccccc|}
\hline WBC & $\begin{array}{c}\text { Sensitivity } \\
(95 \% \mathrm{Cl})\end{array}$ & $\begin{array}{c}\text { Specificity } \\
(95 \% \mathrm{Cl})\end{array}$ & $+\mathrm{LR}$ & $-\mathrm{LR}$ & $\begin{array}{c}\text { Positive predictive value } \\
(95 \% \mathrm{Cl})\end{array}$ & $\begin{array}{c}\text { Negative predictive } \\
\text { value }(95 \% \mathrm{Cl})\end{array}$ \\
\hline$>10 \times 10^{3}$ & $83.33(51.59-97.91)$ & $38.71(26.60-51.93)$ & 1.36 & 0.43 & $20.83(16.03-26.62)$ & $92.31(76.52-97.79)$ \\
\hline
\end{tabular}


are serious complications of ERCP, our clinical approach is to hospitalize these patients and to follow up for $24 \mathrm{~h}$. In this aspect, this study differs from the literature, where the patients were under control of the clinician, and all the laboratory results were obtained in an inpatient clinic. Furthermore, emergent patients hospitalized for obstructive jaundice or cholangitis (not biliary pancreatitis) are assessed accordingly. The most commonly accepted definition of pancreatitis is an amylase level more than 3 times the upper normal limit with new or worsening abdominal pain $[3,9,18,19]$. Post-procedural hyperamylasemia is seen in up to $75 \%$ of patients [20]. Less than 1.5 times the upper normal limit observed at 2-4 h after ERCP is not thought to indicate PEP [21]. In the present study, post-ERCP hyperamylasemia (any level, not only 3 times the upper limit) was detected at $6 \mathrm{~h}$ in 75 (30.8\%) of 243 consecutive patients receiving first time ERCP for choledocholithiasis. The range of detected amylase levels was between 190 and 852 with a mean of $468 \mathrm{U} /$. Only 12 (16\%) of hyperamylasemia developing patients had PEP. Two (2.7\%) patients with an amylase level less than 3 times the upper normal limit (226 and 294) 6 hours after ERCP had PEP. Overall incidence of pancreatitis in the 243 patients was $4.9 \%$. According to Kochar's meta-analysis [22], PEP incidence of 108 randomized controlled trials with 13296 patients was found to be $9.7 \%$ and $14.7 \%$ for high risk patients, with a mortality rate of $0.7 \%$. In our series, all of the PEP patients had mild pancreatitis and responded well to I.V. fluids without anything given orally; mortality was zero. Still, cessation of oral feeding with I.V. fluid infusion is an effective treatment of PEP.

At $24 \mathrm{~h}$ after ERCP, the presence of abdominal pain determined the requirement for re-repeat laboratory values; otherwise, the patients were discharged. The patients who experienced abdominal pain also had increased levels of amylase, CRP and WBC. This is likely due to pancreatic inflammation and is consistent with the literature.

In our study, a history of pre-ERCP cholangitis requiring emergent care and procedural Wirsung duct cannulation requiring contrast media opacification were found to be statistically significant factors for the development of PEP (cholangitis: $p=0.048$, Wirsung cannulation: $p=0.019)$. Pre-ERCP cholangitis is not mentioned as a risk factor in most studies about PEP, but Wirsung cannulation, although there are inconsistent data, was found as a risk factor for PEP.
Guidewire use and pancreatic duct stent placement were recommended in several studies [9, 23, 24]. However, it must be kept in mind that the number of attempts and pancreatic stents also affect the incidence rate of PEP. As a last point, in the latest literature the data about the follow-up timing for the development of PEP is scarce. However, when we evaluate studies which suggest that amylase/lipase levels obtained at the $4^{\text {th }}$ hour may predict PEP, a common method of prediction suggested in the last 15-20 years, we see that the physical evaluation may not be meaningful at this post-procedural time $[25,26]$. Our study reveals that abdominal evaluation of pain is meaningful at the $12^{\text {th }} \mathrm{h}$.

\section{Conclusions}

Amylase level increase was most apparent $12 \mathrm{~h}$ after ERCP and significantly higher $(p<0.001)$ for the development of PEP. The first abdominal pain evaluation and examination is meaningful at the 12-hour timepoint because insufflation during the procedure and other causes of abdominal pain may result in misinterpretation.

\section{Conflict of interest}

The authors declare no conflict of interest.

\section{References}

1. Ahmed M, Konatra R, Savani GT, et al. utilization trends in patient endoscopic retrograde cholangiopancreatography (ERCP): a cross sectional US experience. Endosc Int Open 2017; 5: E261-71.

2. Solomon S, Baillie J. Indications for and Contraindications to ERCP. In: ERCP (3rd Edition). Baron TH, Kozarek RA, Carr-Locke D (eds). Elsevier 2019.

3. Szary NM, Al-Kawas FH. Complications of endoscopic retrograde cholangiopancreatography: how to avoid and manage them. Gastroenterohepatology 2013; 9: 496-504.

4. Katsinelos P, Lazaraki G, Catzimavroudis G, et al. Risk Factors for therapeutic ERCP-related complications: an analysis pf 2.715 cases performed by a single endoscopist. Ann Gastroenterol 2014; 27: 65-72.

5. Li GZ, Wang F, Fang J, et al. Risk factors for post-endoscopic retrograde cholangiopancreatography pancreatitis: evidence from 1786 cases. Med Sci Monit 2018; 24: 8544-52.

6. LaFerla G, Gordon S, Archibald M, et al. Hyperamylasaemia and acute pancreatitis following endoscopic retrograde cholangiopancreatography. Pancreas 1986; 1: 160-3.

7. Cotton PB, Lehman G, Vennes J, et al. Endoscopic sphincterotomy complications and their management: an attempt at consensus. Gastrointest Endosc 1991; 37: 383-93. 
8. Foster BR, Jensen KK, Bakis G, et al. Revised Atlanta classification for acute pancreatitis: a pictorial essay. Radiographics 2016; 36: 675-87.

9. Thaker AM, Mosko JD, Berzin TM. Post-endoscopic retrograde cholangiopancreatography pancreatitis. Gastroenterol Rep 2015; 3: 32-40.

10. Freeman ML. Post-ERCP pancreatitis: patient and technique-related risk factors. JOP 2002; 3: 169-76.

11. Pezzilli R, Romboli E, Campana D, et al. Mechanisms involved in the onset of post-ERCP pancreatitis. JOP 2002; 3: 162-8.

12. Cheng CL, Sherman S, Watkins JL, et al. Risk factors for postERCP pancreatitis: a prospective multicenter study. Am J Gas troenterol 2006; 101: 139-47.

13. Williams EJ, Taylor S, Fairclough P, et al. Risk factors for complication following ERCP; results of a large-scale, prospective multicenter study. Endoscopy 2007; 39: 793-801.

14. Boender J, Nix GA, de Ridder MA, et al. Endoscopic sphincterotomy and biliary drainage in patients with cholangitis due to common bile duct stones. Am J Gastroenterol 1995; 90: 233-8.

15. Tan M, Schaffalitzky de Muckadell OB, Laursen SB. Association between early ERCP and mortality in patients with acute cholangitis. Gastrointest Endosc 2018; 87: 185-92.

16. Xu MM, Carr-Locke DL. Early ERCP for severe cholangitis? Of course! Gastrointest Endosc 2018; 87: 193-95.

17. Vandervoort J, Soetikno RM, Tham TC, et al. Risk factors for complications after performance of ERCP. Gastrointest Endosc 2002; 56: 652-6.

18. ASGE Standards of Practice Committee, Chandrasekhara V, Khashab MA, Muthusamy VR, et al. Adverse events associated with ERCP. Gastrointest Endosc 2017; 85: 32-47.

19. Freeman ML, Nelson DB, Sherman S, et al. Complications of endoscopic biliary sphincterotomy. N Engl J Med 1996; 335: 909-18.

20. Freeman ML, Guda NM. Prevention of post-ERCP pancreatitis: a comprehensive review. Gastrointest Endosc 2004; 59: 845-64.

21. Thomas PR, Sengupta S. Prediction of pancreatitis following endoscopic retrograde cholangiopancreatography by the 4-h post procedure amylase level. J Gastroenterol Hepatol 2001; 16: 923-6.

22. Kochar B, Akshintala VS, Afghani E, et al. Incidence, severity, and mortality of post-ERCP pancreatitis: a systematic review by using randomized, controlled trials. Gastrointest Endosc 2015; 81: 143-9.

23. Nakai Y, Isayama H, Sasahira N, et al. Risk factors for post-ERCP pancreatitis in wire guided cannulation for therapeutic biliary ERCP. Gastrointest Endosc 2015; 81: 119-26.

24. Sugimoto M, Takagi T, Suzuki R, et al. Pancreatic stents for the prevention of post-endoscopic retrograde cholangiopancreatography pancreatitis should be inserted up to the pancreatic body or tail. World I Gastroenterol 2018; 24: 2392-9.

25. Lee YK, Yang MJ, Kim SS, et al. Prediction of post-endoscopic retrograde cholangiopancreatography pancreatitis using 4-hour post-endoscopic retrograde cholangiopancreatography serum amylase and lipase levels. J Korean Med Sci 2017; 32: 1814-9.

26. Minakari M, Sebghatollahi V, Sattari M, et al. Serum amylase and lipase levels for prediction of postendoscopic retrograde cholangiopancreatography pancreatitis. J Res Med Sci 2018; 6: 23:54.

Received: 22.11.2019, accepted: 13.03.2020. 